Original Articles

\title{
Decreased Plasma Adiponectin Levels in Young Obese Males
}

\author{
Taketaka Hara¹, Hiroshi Fujiwara ${ }^{1}$, Tetsuo Shoji², Tatsuya Mimura ${ }^{3}$, Hayato Nakao ${ }^{1}$, \\ and Shigeo Fujimoto ${ }^{1}$ \\ ${ }^{1}$ Department of Sports Medicine, Graduate School of Medicine, \\ ${ }^{2}$ Department of Metabolism, Endocrinology and Molecular Medicine, Graduate School of Medicine, \\ ${ }^{3}$ Doctoral Program of Human Life Science, Osaka City University, Osaka, Japan.
}

\begin{abstract}
Plasma adiponectin levels are reduced in middle-aged obesity and in patients with type 2 diabetes and coronary artery disease. The purpose of this study was to investigate the effects of early-aged obesity on plasma adiponectin level. Twenty-six male college students (19.2 \pm 1.1 years, obese group: $n=15$, [body mass index $>25$, percent body fat $>25 \%$ ], non-obese group: $n=11$ ) participated in the present study. We measured anthropometric parameters and plasma adiponectin and leptin level. Plasma adiponectin levels in the obese group were significantly lower than those in the nonobese group (obese: $4.7 \pm 2.0 \mu \mathrm{g} / \mathrm{ml}$, non-obese: $6.8 \pm 2.2 \mu \mathrm{g} / \mathrm{ml}, p<0.05$ ). On the other hand, plasma leptin levels in the obese group were significantly higher than those in the non-obese group (obese: $8.4 \pm 3.2 \mathrm{ng} / \mathrm{ml}$, non-obese: $2.6 \pm 2.1 \mathrm{ng} / \mathrm{ml}, p<$ $0.001)$. Plasma adiponectin levels were significantly correlated with body weight $(r=$ $-0.415, p<0.05)$ and percent body fat $(r=-0.412, p<0.05)$. Stepwise multiple regression analysis revealed that percent body fat was a significant independent predictor of plasma adiponectin level $(r=0.406, p<0.05)$. These results show that obesity is associated with reduced plasma adiponectin even in young subjects. J Atheroscler Thromb, 2003; 10: 234-238.
\end{abstract}

Key words: Adiponectin, Leptin, Early aged obesity, Body fat

\section{Introduction}

Obesity is defined as an accumulation of excess body fat, and is one of the risk factors for lifestyle-related diseases such as type 2 diabetes, hypertension, and coronary artery disease (CAD) (1). Adipose tissue has long been misconstrued as a mere tissue of fat storage. In recent studies, however, it was reported that the character of regional fat is heterogeneous with respect to lipid and glucose metabolism (2), and adipose tissue secretes a variety of biologically active molecules (adipocytokine), including leptin (3), tumor necrosis factor- $\alpha(\mathrm{TNF}-\alpha)(4)$,

Address for correspondence: Taketaka Hara, Department of Sports Medicine, Graduate School of Medicine, Osaka City University, 1-4-3, Asahimachi, Abeno-ku, Osaka, Osaka 545-8585, Japan

E-mail: m1392192@med.osaka-cu.ac.jp

Received January 10, 2003

Accepted March 25, 2003 plasminogen activator inhibitor-1 (PAI-1) (5) and adiponectin (6). By secreting adipocytokines, adipose tissue plays active roles in energy homeostasis and other physiological functions $(7,8)$.

Functions of adiponectin include reducing TNF- $\alpha$-induced macrophage attachment to endothelial cells, and suppressing the secretion of TNF- $\alpha$ from human monocyte-macrophages (6). These functions of adiponectin may protect against vascular injury as an early event in the atherosclerotic process (9). Furthermore, reduction in plasma levels of adiponectin is related to the development of insulin resistance (10). In fact, plasma adiponectin levels are decreased in patients with type 2 diabetes and $\operatorname{CAD}(9,11,12)$. Moreover, plasma adiponectin levels are lower in middle-aged obese than in non-obese subjects (6). Thus, reduced adiponectin in obesity plays an important role in the development of insulin resistance and vascular disorders.

Lifestyle-related disease is induced by excessive eat- 
ing or salt intake, lack of exercise, and smoking history from an early age. Therefore, early lifestyle might affect plasma adiponectin levels. Importantly, an inverse association between adiponectin and obesity was reported among middle-aged subjects $(6,11,12)$. It is important to examine whether such a relation is present in young people, because young obese subjects may be exposed to potentially atherosclerotic conditions longer than older subjects. Only one study by Kazumi et al. (13) reported the adiponectin concentration in young people. Therefore, in the present study, we investigated the relation between early aged obesity and plasma adiponectin levels in young obese and non-obese subjects.

\section{Methods}

\section{Subjects}

Twenty-six sedentary male subjects (mean [ \pm S.D.] age, $19.2 \pm 1.1$ years) participated in this study. In advance, we measured blood pressure, plasma levels of insulin, triglyceride, total-cholesterol, HDL-cholesterol, and fasting blood sugar to confirm that no patients with diabetes, hyperlipidemia or hypertension participated in this study. None of the subjects had a history of smoking.

In this study obesity was defined as a body mass index (BMI) greater than 25 according to the Japan Society for the Study of Obesity (2000), and with it the subjects were separated into two groups (obese group: $n=15$, nonobese group: $n=11$ ) (Table 1). Written informed consent was obtained from each individual.

\section{Biochemical and anthropometric measurements}

Plasma adiponectin levels were determined by an enzymelinked immunosorbent assay (ELISA) system as described previously (6). Plasma leptin levels were measured with a radioimmunoassay kit (Human Leptin RIA Kit, Cosmic Co. Ltd, Tokyo, Japan). Body composition including percent body fat, fat mass, percent body muscle and muscle mass was measured by the bioelectrical impedance method (Muscle- $\alpha$, Art Heaven 9 Co. Ltd, Kyoto, Japan).

\section{Statistical analysis}

Values were presented as means \pm SD. Difference between groups was examined by the unpaired Student's $t$ test. Liner relations among variables were tested using Pearson's correlation coefficients. Stepwise multiple regression analysis was performed that included body weight, BMI, percent body fat, body fat mass and muscle volume as independent variables and plasma adiponectin and leptin level as dependent variables, respectively. $P$ values $<0.05$ were considered significant.

\section{Results}

\section{Plasma leptin level and correlation with body composition}

Table 1 shows the results of biochemical and anthropometric measurements in the obese and non-obese groups. Mean plasma leptin levels in the obese group were significantly higher than that in the non-obese group (Fig 1). Plasma leptin levels were significantly correlated with body weight $(r=0.811, p<0.001)$, percent body fat $(r=0.878, p<0.001)$ (Fig. 2), body fat mass $(r=0.881, p$ $<0.001)$, BMI $(r=0.871, p<0.001)$, and muscle volume $(r=0.524, p<0.01)$. Stepwise multiple regression analysis revealed that body fat mass was independently correlated with plasma leptin level $\left(r^{2}=0.805, p<0.001\right)$.

\section{Plasma adiponectin level and correlation with body composition}

Plasma adiponectin levels in the obese group were significantly lower than that in the non-obese group (Fig. 1). Moreover, plasma adiponectin levels were negatively but significantly correlated with body weight $(r=-0.415, p<$ $0.05)$, percent body fat $(r=-0.412, p<0.05)$ and body fat mass $(r=-0.416, p<0.05)$ (Fig. 2). No significant correlation was observed between plasma adiponectin level and BMI $(r=-0.360)$ or muscle volume $(r=-0.346)$. Stepwise multiple regression analysis revealed that percent body fat was independently correlated with plasma adiponectin level $\left(r^{2}=0.165, p<0.05\right)$. No significant cor-

Table 1. Physical characteristics and adipocytokine levels of subjects.

\begin{tabular}{|c|c|c|c|c|c|c|}
\hline & & \multicolumn{2}{|c|}{ obese $(n=15)$} & \multicolumn{2}{|c|}{ non-obese $(n=11)$} & \multirow{2}{*}{$P$ value } \\
\hline & & Mean & S.D. & Mean & S.D. & \\
\hline Age & years & 19.5 & 1.0 & 18.8 & 1.2 & N.S. \\
\hline Height & $\mathrm{cm}$ & 172.6 & 6.9 & 171.8 & 5.0 & N.S. \\
\hline Weight & $\mathrm{kg}$ & 93.0 & 13.8 & 64.6 & 5.0 & $<0.001$ \\
\hline $\mathrm{BMI}$ & $\mathrm{kg} / \mathrm{m}^{2}$ & 31.2 & 4.1 & 22.0 & 2.3 & $<0.001$ \\
\hline$\%$ body fat & $\%$ & 28.7 & 3.3 & 13.7 & 3.5 & $<0.001$ \\
\hline Body fat mass & $\mathrm{kg}$ & 27.0 & 6.8 & 9.0 & 2.7 & $<0.001$ \\
\hline Muscle volume & $\mathrm{kg}$ & 30.3 & 5.6 & 25.4 & 2.7 & 0.010 \\
\hline Adiponectin & $\mu \mathrm{g} / \mathrm{ml}$ & 4.7 & 2.0 & 6.5 & 2.2 & 0.033 \\
\hline Leptin & $\mathrm{ng} / \mathrm{ml}$ & 8.4 & 3.2 & 2.6 & 2.1 & $<0.001$ \\
\hline
\end{tabular}

$P$ value are analyzed using unpaired $t$ test. 

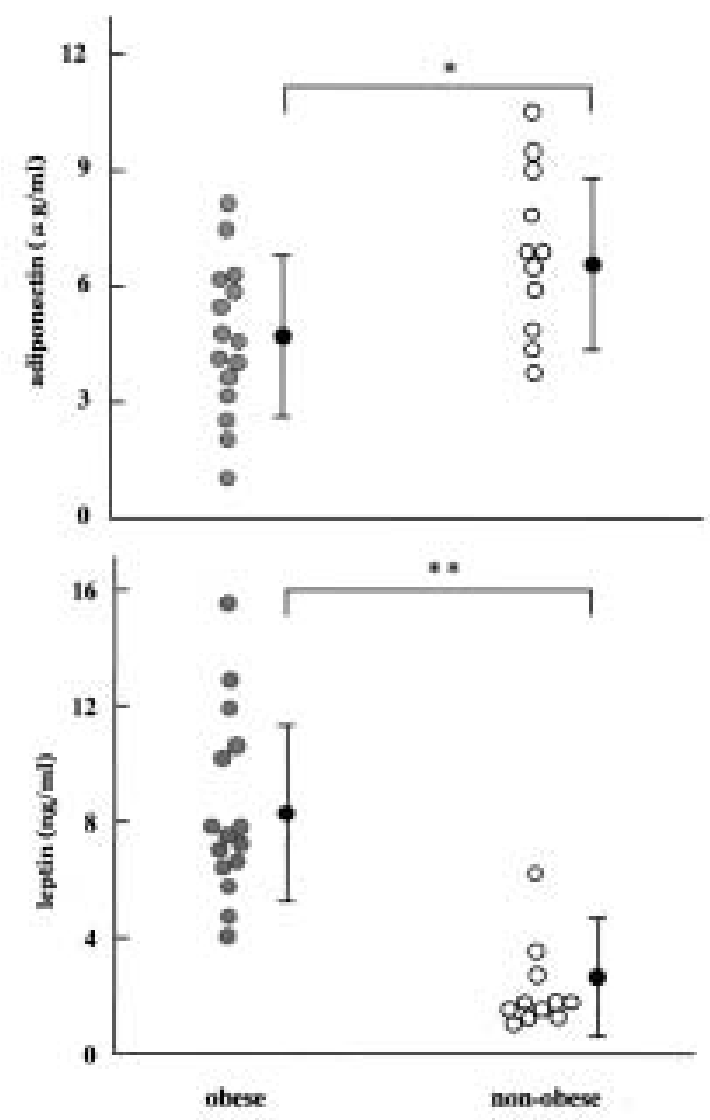

Fig. 1. Plasma levels of adiponectin and leptin in obese $(O$ : $n=15)$ and non-obese $(O: n=11)$ subjects.

$*: p<0.05, * *: p<0.001$
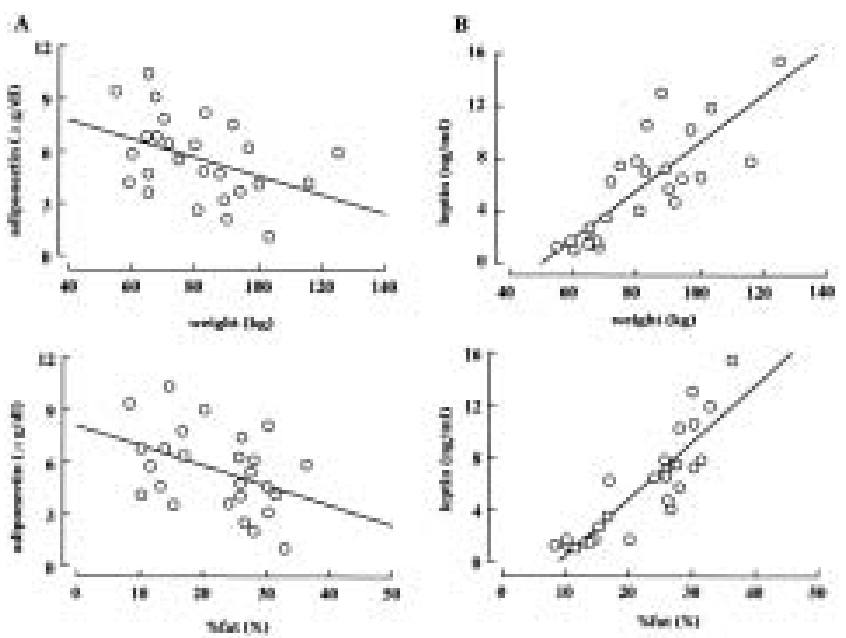

Fig. 2. A: Correlations between plasma level of adiponectin and body weight $(r=-0.415, p<0.05)$ and \%body fat $(r=-0.412$, $p<0.05)$ in obese and non-obese subjects. B: Correlations between plasma level of leptin and body weight $(r=0.811, p<$ $0.001)$ and \%body fat $(r=0.878, p<0.001)$ in obese and nonobese subjects. relation was observed between plasma adiponectin and leptin.

\section{Discussion}

In this study, in young subjects, plasma adeponectin levels were significantly reduced in obese subjects compared with non-obese subjects, although no subjects had diabetes, hyperlipidemia or hypertension. Previous studies about adiponectin investigated middle-aged subjects with hyperinsulinemia or CAD, and obesity $(9,11,12)$, reported these subjects showed low plasma adiponectin levels. However, there have been few studies about plasma level of adiponectin in young subjects. Since young obese males have low adiponectin levels, obesity is one of the risk factors to reduce the plasma adiponectin levels in young subjects.

It was reported that plasma adiponectin levels in middleaged obese subjects were lower than that in non-obese subjects, although adiponectin is secreted only from adipose tissue (6). The mechanism of reduction about plasma adiponectin levels in patients with obesity has not been clearly determined. However, in middle-aged subjects, the increase of plasma adiponectin levels accompanied a reduction of body weight by gastric surgery $(14,15)$ or dietary therapy $(11,16)$. On the other hand, there was no significant change in plasma adiponectin levels with exercise training that did not alter body mass (15). In the present study, plasma adiponectin levels were negatively correlated with percent body fat and body fat mass, and percent body fat was the only independent variable on stepwise multiple regression analysis. Thus, body composition may be one of the important factors adjusting plasma adiponectin levels.

In a previous study, plasma levels of leptin in young subjects were correlated with \%body fat (17). Moreover, body fat mass, calculated insulin resistance (HOMA-ratio) and triglyceride were significant determinants of leptin concentration by multiple regression analysis (18). In the present study, plasma leptin levels were increased in obese subjects, and were positively correlated with body fat mass. Leptin also affected insulin sensitivity and development of hypertension (19-21), and plasma leptin levels were decreased by weight reduction $(22,23)$. Obese subjects showed low adiponectin levels and high leptin levels compared with non-obese subjects in the present study.

It was unclear if these cytokines will affect the development of diabetes and atherosclerosis in the future. However, Hotta et al. (10) reported that plasma adiponectin levels were reduced in parallel with the progression of insulin resistance in rhesus monkeys. It was also reported that plasma adiponectin levels were decreased in obesity and in patients with diabetes in middle-aged sub- 
jects $(6,11,12)$. Therefore, a long standing low adiponectin level from an early age may cause insulin sensitivity and atherosclerosis. Further investigations will be needed about the effects of combinations of exercise training and dietary therapy to plasma levels of adiponectin and leptin in young obese subjects.

In conclusion, plasma adiponectin levels were already reduced in young male obese subjects, and were correlated with body fat. The present findings suggest that obesity in young people causes an atherogenic adipocytokine profile similar to that in middle-aged subjects. This observation has a potential importance for the prevention of atherosclerosis.

Acknoledgements: We thank the staff of Otsuka Pharmaceutical Company, Ltd. Otsuka Assay Laboratories for their technical assistance in this study.

\section{References}

(1) Must A, Spadono J, Coakley EH, Field AE, Cclditz $G$, and Dietz WH: The disease burden associated with overweight and obesity. JAMA, 282: 15231529, 1999

( 2 ) Ohsuzu F, Takayama E, Hayashi K, Yanagida S, Nomi M, Kosuda S, Kusano S, and Nakamura H: Relation of abdominal and thigh adipose tissue distribution to serum lipids and glucose metabolism in obese males. J Atheroscler Thromb, 4: 34-39, 1997

(3) Mantzoros CS: The role of leptin in human obesity and disease: a review of current evidence. Ann Intern Med, 130: 671-680, 1999

(4) Mantzoros CS, Moschos S, Avramopoulos I, Kaklamani V, Liolios A, Doulgerakis DE, Griveas I, Katsilambros N, and Flier JS: Leptin concentrations in relation to body mass index and the tumor necrosis factor-alpha system in humans. J Clin Endocrinol Metab, 82: 3408-3413, 1997

( 5 ) Mavri A, Stegnar M, Krebs M, Sentocnik JT, Geiger $M$, and Binder BR: Impact of adipose tissue on plasma plasminogen activator inhibitor-1 in dieting obese women. Arterioscler Thromb Vasc Biol, 19: 1582-1587, 1999.

(6) Arita Y, Kihara S, Ouchi N, Takahashi M, Maeda K, Miyagawa J, Hotta K, Shimomura I, Nakamura T, Miyaoka K, Kuriyama H, Nishida M, Yamashita S, Okubo K, Matsubara K, Muraguchi M, Ohmoto Y, Funahashi T, and Matsuzawa Y: Paradoxical decrease of an adipose-specific protein, adiponectin, in obesity. Biochem Biophys Res Commun, 257: 79-83, 1999

( 7 ) Matsuzawa Y, Funahashi T, and Nakamura T: Molecular mechanism of metabolic syndrome X: contribution of adipocytokines adipocyte-derived bioactive substances. Ann N Y Acad Sci, 892: 146-
154, 1999

( 8 ) Funahashi T, Nakamura T, Shimomura I, Maeda K, Kuriyama H, Takahashi M, Arita Y, Kihara S, and Matsuzawa Y: Role of adipocytokines on the pathogenesis of atherosclerosis in visceral obesity. Intern Med, 38: 202-206, 1999

( 9 ) Ouchi N, Kihara S, Arita Y, Maeda K, Kuriyama H, Okamoto Y, Hotta K, Nishida M, Takahashi M, Nakamura T, Yamashita S, Funahashi T, and Matsuzawa Y: Novel modulator for endothelial adhesion molecules: adipocyte-derived plasma protein adiponectin. Circulation, 100: 2473-2476, 1999

(10) Hotta K, Funahashi T, Bodkin NL, Ortmeyer HK, Arita Y, Hansen BC, and Matsuzawa Y: Circulating concentrations of the adipocyte protein adiponectin are decreased in parallel with reduced insulin sensitivity during the progression to type 2 diabetes in rhesus monkeys. Diabetes, 50: 1126-1133, 2001

(11) Hotta K, Funahashi T, Arita Y, Takahashi M, Matsuda M, Okamoto $\mathrm{Y}$, Iwahashi $\mathrm{H}$, Kuriyama $\mathrm{H}$, Ouchi N, Maeda K, Nishida M, Kihara S, Sakai N, Nakajima T, Hasegawa K, Muraguchi M, Ohmoto Y, Nakamura T, Yamashita S, Hanafusa T, and Matsuzawa Y: Plasma concentrations of a novel, adipose-specific protein, adiponectin, in type 2 diabetic patients. Arterioscler Thromb Vasc Biol, 20: 1595-1599, 2000

(12) Weyer C, Funahashi T, Tanaka S, Hotta K, Matsuzawa Y, Pratley RE, and Tataranni PA: Hypoadiponectinemia in obesity and type 2 diabetes: close association with insulin resistance and hyperinsulinemia. J Clin Endocrinol Metab, 86: 1930-1935, 2001

(13) Kazumi T, Hirano T, Kawaguchi A, Yoshino G, and Sakai K: Young men with high-normal blood pressure have lower serum adiponectin, smaller LDL size, and higher elevated heart rate than those with optimal blood pressure. Diabetes care, 25: 971-976, 2002

(14) Yang WS, Lee WJ, Funahashi T, Tanaka S, Matsuzawa Y, Chao CL, Chen CL, Tai TY, and Chuang LM : Weight reduction increases plasma levels of an adipose-derived anti-inflammatory protein, adiponectin. J Clin Endocrinol Metab, 86: 3815-3819, 2001

(15) Hulver MW, Zheng D, Tanner CJ, Houmard J.A, Kraus WE, Slents CA, Sinha MK, Pories WJ, MAcDonald KG, and Dohm GL: Adiponectin is not altered with exercise training despite enhanced insulin action. Am J Physiol Endocrinol Metab, 283: E861-E865, 2002

(16) Hirose H, Kawai T, Yamamoto $Y$, Taniyama M, Tomita M, Matsubara K, Okazaki Y, Ishii T, Oguma Y, Takei I, and Saruta T: Effects of pioglitazone on metabolic parameters, body fat distribution, and 
serum adiponectin levels in Japanese male patients with type 2 diabetes. Metabolism, 51: 314-317, 2002

(17) Echwald SM, Clausen JO, Hansen T, Urhammer SA, Hansen L, Dinesen B, and Borch JK: Analysis of the relationship between fasting serum leptin levels and estimates of beta-cell function and insulin sensitivity in a population sample of 380 healthy young Caucasians. Eur J Endocrinol, 140: 180-185, 1999

(18) Matsubara M, Chiba H, Maruoka S, and Katayose S: Elevated serum leptin concentrations in women with components of multiple risk factor clustering syndrome. J Atheroscler Thromb, 7: 231-237, 2000

(19) Shimomura I, Hammer RE, Ikemoto S, Brown MS, and Goldstein JL: Leptin reverses insulin resistance and diabetes mellitus in mice with congenital lipodystrophy. Nature, 401: 73-76. 1999

(20) Asakawa H, Tokunaga K, and Kawakami F: Rela- tionship of leptin level with metabolic disorders and hypertension in Japanese type 2 diabetes mellitus patients. J Diabetes Complications, 15: 57-62, 2001

(21) Henriksen JH, Holst JJ, Moller S, Andersen UB, Bendtsen F, and Jensen G: Elevated circulating leptin levels in arterial hypertension: relationship to arteriovenous overflow and extraction of leptin. Clin Sci (Lond), 99: 527-534, 2000

(22) Considine RV, Sinha MK, Heiman ML, Kriauciunas A, Stephens TW, Nyce MR, Ohannesian JP, Marco CC, McKee LJ, Bauer TL, and Caro JF: Serum immunoreactive-leptin concentrations in normalweight and obese humans. N Engl J Med, 334: 292295, 1996

(23) Halle M, Berg A, Garwers U, Grathwohl D, Knisel $\mathrm{W}$, and Keul J: Concurrent reductions of serum leptin and lipids during weight loss in obese men with type II diabetes. Am J Physiol, 277: E277-282, 1999 